\title{
Rice increases phosphorus uptake in strongly sorbing soils by intra-root facilitation
}

\author{
Christian W. Kuppe ${ }^{1,2}$, Guy J D Kirk ${ }^{3}$, Matthias Wissuwa ${ }^{1,4}$, and Johannes A Postma ${ }^{1}$ \\ ${ }^{1}$ Institute of Bio-and Geosciences -Plant Sciences (IBG-2), Forschungszentrum Jülich \\ $\mathrm{GmbH}$ \\ ${ }^{2}$ RWTH Aachen University \\ ${ }^{3}$ School of Water, Energy and Environment, Cranfield University \\ ${ }^{4}$ Crop, Livestock and Environment Division, International Research Center for Agricultural \\ Sciences, Correspondence Christian Kuppe
}

November 29, 2021

\begin{abstract}
Upland rice (Oryza sativa) is adapted to strongly phosphorus (P) sorbing soils. The mechanisms underlying $\mathrm{P}$ acquisition, however, are not well understood, and models typically underestimate uptake. This complicates root ideotype development and trait-based selection for further improvement. We present a novel model, which correctly simulates the P uptake by a P-efficient rice genotype measured over 48 days of growth. The model represents root morphology at the local rhizosphere scale, including root hairs and fine S-type laterals. It simulates fast-and slowly reacting soil $\mathrm{P}$ and the $\mathrm{P}$-solubilizing effect of root-induced $\mathrm{pH}$ changes in the soil. Simulations predict that the zone of $\mathrm{pH}$ changes and $\mathrm{P}$ solubilization around a root spreads further into the soil than the zone of $\mathrm{P}$ depletion. A root needs to place laterals outside its depletion-but inside its solubilization zone to maximize P uptake. S-type laterals, which are short but hairy, appear to be the key root structures to achieve that. Thus, thicker roots facilitate the $\mathrm{P}$ uptake by fine lateral roots. Uptake can be enhanced through longer root hairs and greater root length density but was less sensitive to total root length and root class proportions.
\end{abstract}

\section{Hosted file}

phmodelpaper2021reference_1fjrz7.pdf available at https://authorea.com/users/448508/ articles/547305-rice-increases-phosphorus-uptake-in-strongly-sorbing-soils-by-intraroot-facilitation 